\title{
Наджафова В.А.к. \\ Оценка нарушений субпопуляций лимфоцитов у детей с железодефицитной анемией
}

Азербайджанский Государственный Институт Усовершенствования врачей им. А. Алиева

(Азербайджан, Баку)

doi $10.18411 / g q-31-07-2021-03$

\section{Аннотация}

Статья посвящена проблеме нарушения иммунитета у детей с железодефицитной анемией (ЖДА), проживающих в Азербайджане. Были выявлены более низкие показатели клеточного иммунитета (CD3, CD4, CD8). Относительное количество клеток CD3 в общей группе детей с ЖДА составило $52,7 \pm 4,35 \%$, в контрольной группе - $62,6 \pm 5,49 \%, \mathrm{p}<0,05$.

Проведенные исследования выявили положительную корреляцию клеток CD3, $\mathrm{CD} 4, \mathrm{CD} 8$ с гемоглобином и сывороточным железом. Результаты высокой силы связи коэффициента корреляции сывороточного железа с относительным количеством клеток CD3 и CD4 в общих группах детей с ЖДА $(\mathrm{r}=0,8)$ показали, что дефицит железа играет большую роль для активности клеточного иммунитета. Таким образом, в статье показано ослабление как врожденного (NK-CD56), так и приобретенного (CD3, CD4, $\mathrm{CD} 8)$ компонентов клеточного иммунитета. Полученные результаты могут быть оценены как нарушение иммунного баланса, связанное с недостаточностью клеточного иммунитета у детей с ЖДА.

Ключевые слова: дети, железодефицитная анемия, иммунная система, субпопуляции лимфоцитов.

\section{Abstract}

The article is devoted to the problem of impaired immune balance in children with iron deficiency anemia (IDA) living in Azerbaijan. Were identified lower indicators of cellular immunity (CD3, CD4, CD8). The relative number of CD3 cells in the general group of children with IDA was $52.7 \pm 4.35 \%$, in the control group $-62.5 \pm 5.49 \%$, p $<0.05$. Studies have shown a positive correlation of CD3, CD4, CD8 cells with hemoglobin and serum iron. The results of the high strength of the relationship between the correlation coefficient of serum iron and the relative number of CD3 and CD4 cells in the general groups of children with IDA $(r=0.8)$ showed that iron deficiency plays an important role for the activity of cellular immunity. Thus, the article shows a weakening of both innate (NK-CD56) and acquired (CD3, CD4, CD8) components of cellular immunity. The results obtained can be assessed as a violation of the immune balance associated with a deficiency of cellular immunity in children with IDA.

Keywords: children, iron deficiency anemia, immune system, lymphocyte subpopulations.

Недостаточность железа является наиболее часто встречаемым дефицитом среди всех микроэлементов в человеческой популяции. Также ЖДА занимает первое место среди заболеваний, возникающих при нарушении питания. Самая высокая распространенность $(42,6 \%)$ приходится на детей $[1,2,3]$. Статистические исследования также подтверждают наличие ЖДА среди детей, проживающих в Азербайджане. Железо играет важную роль в нормальном функционировании иммунной системы, в особенности, является ключевым компонентом ферментов, участвующих в процессе деления и роста иммунных клеток. С этой точки зрения, изучение негативного влияния дефицита железа на иммунную систему детей является также одной из актуальных проблем $[4,5]$. 
Таким образом, учитывая возможные изменения иммунного баланса при дефиците железа, оценка субпопуляций лимфоцитов у детей в возрасте от 6 месяцев до 5 лет послужило частью нашего исследования.

Цель работы: исследование субпопуляций лимфоцитов у детей в возрасте от 6 месяцев до 5 лет в Азербайджане, с целью изучения некоторых аспектов влияния ЖДА на клеточный иммунитет.

Материалы и методы: в исследовании были задействованы 123 детей в возрасте от 6 месяцев до 5 лет, амбулаторно поступивших в отделение детской поликлиники Национального Центра Гематологии и Трансфузиологии Азербайджана с сентября 2019 года по февраль 2020 года. По гематологическим и биохимическим показателям крови у 95 детей (58 мальчиков, 37 девочек) в возрасте от 6 месяцев до 5 лет была диагностирована анемия различной степени. Из них у 32 детей была диагностирована легкая степень ЖДА, у 37 детей - средняя степень ЖДА, и 26 детей имели тяжелую степень ЖДА. 28 детей (16 мальчиков, 12 девочек) были включены в исследование в качестве контрольной группы. Средний возраст детей с ЖДА составлял $29 \pm 15,6$ месяца, а средний возраст контрольной группы - $26 \pm 16,6$ месяца.

Для достижения цели исследования были использованы следующие методы исследования: для оценки лимфоцитов иммунной системы, проводилось исследование клеточных фракций субпопуляций лимфоцитов плазмы (CD3 - все Т-лимфоциты, CD4 - T-хелперы, CD8 - цитотоксические T-супрессоры, CD19 - В-лимфоциты, CD56 природные клетки-киллеры) иммунофлюоресцентным методом (панель моноклональных антител, ООО «Сорбент», Россия) (Центральная научноисследовательская лаборатория Азербайджанского Государственного Института Усовершенствования Врачей имени А. Алиева).

Результаты и их обсуждение. Результаты были получены в группе детей с ЖДА: $\mathrm{HgB} 94,59 \pm 3,23$ г/л в группе с легкой степенью ЖДА, 82,3 \pm 5,35 г/л в группе со средней степенью ЖДА, 64,04 \pm 6,64 г/л в группе с тяжелой степенью ЖДА и $118.04 \pm$ 5.01 г/л - в контрольной группе.

В нашем исследовании общее относительное количество (\%) Т-лимфоцитов (CD3) в группе с ЖДА было значительно ниже, чем в контрольной группе, что свидетельствует об отсутствии механизмов защиты Т-клеток, которые иммунологически контролируют антигенный гомеостаз в организме. CD3 (все Тлимфоциты) в общей группе с ЖДА составил $52,7 \pm 4,35 \%$, в контрольной группе $62,6 \pm 5,49 \%, \mathrm{p}<0,05$. В ходе исследования измерялась величина коэффициента корреляции относительного количества клеток CD3 с гематологическими показателями крови (гемоглобин, сывороточное железо). В общей группе с ЖДА относительное количество клеток CD3 имело среднюю силу связи коэффициента корреляции с гемоглобином $(\mathrm{r}=0,74)$ и сильную силу связи $(\mathrm{r}=0,8)$ с сывороточным железом.

Относительное количество Т-хелперов (CD4) (\%) в общей группе с ЖДА 27,1 \pm $2,78 \%$, а в контрольной группе $31,6 \% \pm 6,0 \%, \mathrm{p}<0,05$. Относительное количество клеток CD4 также коррелировало с гемоглобином и сывороточным железом. Согласно результатам, величины коэффициентов корреляции в общей группе с ЖДА были $\mathrm{r}=0,63$ и $\mathrm{r}=0,8$, соответственно.

В группах с ЖДА также наблюдалось снижение уровня Т-цитотоксических супрессоров с поверхностным маркером CD8. Таким образом, оно составило 22,4 \pm $2,38 \%$ в общей группе с ЖДА и $24,7 \pm 4,02 \%$ в контрольной группе, $p<0,05$. Результаты корреляции $\mathrm{CD} 8$ лимфоцитов с гемоглобином и сывороточным железом составляли соответственно $\mathrm{r}=0.53, \mathrm{r}=0.61$. Соотношение $\mathrm{CD} 4 / \mathrm{CD} 8$ составило $1,21 \pm 0,11 \%$ в общей группе с ЖДА и $1,29 \pm 0,16 \%$ в контрольной группе. Была получена слабая сила связи коэффициента корреляции индекса $\mathrm{CD} 4 / \mathrm{CD} 8$ с гемоглобином и сывороточным железом, оценка результатов была несущественной. 
Относительное количество CD56+ (\%) в общей группе с ЖДА $12.5 \pm 2.14 \%$, а в контрольной группе $31.7 \% \pm 2.27 \%$. Это говорит об ослаблении цитолитической активности клеток CD56+. Разница в статистической точности для всех групп ЖДА клеток CD56+ составила $\mathrm{p}<0,05$ по сравнению с контрольной группой. Была получена средняя сила связи коэффициента корреляции клеток CD56+ с гемоглобином и сывороточным железом в общей группе ЖДА $\mathrm{r}=0.43$ и $\mathrm{r}=0.32$ соответственно.

\section{Заключение:}

Таким образом, для детей с ЖДА наблюдалась типичная картина:

- По мере увеличения тяжести ЖДА у детей наблюдалось значительное ослабление клеточного компонента приобретенного иммунитета (CD3, CD4, CD8). Высокая положительная корреляция сывороточного железа с относительным количеством клеток CD3 и CD4 в общей группе с ЖДА $(\mathrm{r}=0,8)$ показала, что дефицит железа играет важную роль при ослаблении клеточного иммунитета.

- Дефицит также наблюдался в других естественных клетках-киллерах CD56, которые являются индикаторами врожденного иммунитета. Результаты могут быть оценены как нарушение иммунного баланса, связанное с дефицитом клеточного иммунитета у детей с ЖДА.

1. World Health Organization. Nutritional anaemias: tools for effective prevention and control. Geneva: World Health Organization. - 2017.

2. Kehl-Fie, TE, Skaar, EP. Nutritional immunity beyond iron: a role for manganese and zinc. Curr Opin Chem Biol. 2010; 14:218-224.

3. Eugene D Weinberg. Iron Availability and Infection. Biochim Biophys Acta. doi: 10.1016/j.bbagen.2008.07.002. Epub 2008 Jul 14.

4. Hassan TH, Badr MA, Karam NA, et al. Impact of iron deficiency anemia on the function of the immune system in children. Medicine (Baltimore). 2016;95(47):e5395. doi:10.1097/MD.0000000000005395

5. Hennigar SR, Mc Clung JP. Nutritional Immunity: Starving Pathogens of Trace Minerals. Am J Lifestyle Med. 2016;10(3):170-173. Published 2016 Feb 4. doi:10.1177/1559827616629117

\section{Сметанин B.H. \\ Эффективность современных технологий инфекционной безопасности в профилактике ИСМП}

Рязанский государственный медицинский университет имени академика И.П. Павлова

(Россия, Рязань)

doi 10.18411/gq-31-07-2021-04

\section{Аннотация}

Инфекции, связанные с оказанием медицинской помощи, представляют важную медицинскую и социальную проблему, так как и в настоящее время занимают одно из первых мест в структуре материнской заболеваемости и смертности. Применение новых диагностических и лечебных технологий позволило существенно уменьшить число тяжелых форм гнойно-воспалительных заболеваний и летальность от них.

Ключевые слова: инфекции, оказание медицинской помощи, заболеваемость, медицинское учреждение, инфекционная безопасность.

\section{Abstract}

Infections associated with the provision of medical care are an important medical and social problem, since they currently occupy one of the first places in the structure of maternal morbidity and mortality. The use of new diagnostic and therapeutic technologies has significantly reduced the number of severe forms of purulent-inflammatory diseases and cases of subsequent mortality.

Keywords: infections, medical care, morbidity, medical institution, infectious safety. 